\title{
EPITAFIOS ÁRABES DE TAIFAS, CUATRO VALENCIANOS Y DOS DE TOLEDO
}

\author{
Carmen Barceló \\ Universitat de València
}

\begin{abstract}
Resumen: Actualizar la obra de Lévi-Provençal sobre las inscripciones árabes de España requiere un esfuerzo previo de revisión y puesta al día de las antiguas ediciones de los epígrafes, además de la incorporación de otros muchos. Se ofrece aquí la edición, traducción y estudio de seis inscripciones árabes, todas trabajadas sobre mármol, inéditas unas y conocidas otras sólo en parte. La lectura de sus inscripciones aporta datos históricos y onomásticos de cierta importancia. Entre las novedades epigráficas, el estudio subraya los aspectos propios del cúfico de época taifa en la zona oriental de alAndalus, proporciona dos alfabetos de lápidas datadas y relaciona con el poder político establecido la adopción por el pueblo de nuevos modelos caligráficos.
\end{abstract}

Palabras clave: Epigrafía árabe, Epitafios, Al-Andalus, Valencia. Siglo XI.

\section{Arabic Taifa epitaphs. Four from Valencia, two from Toledo}

Abstract: The updating of the reference book by Levi-Provençal about the Arab inscriptions of Spain requires a prior effort to review and update the old edited texts of the epigraphs as well as to add the correct interpretation of the new findings. In order to facilitate this necessary task, we offer here the edition, translation and study of six unpublished Arabic inscriptions and others known only in part, all engraved on marble. The reading of these epigraphs gives data of some formal, historical and civil importance. Among the interesting new contribution of some of them to the Epigraphy, the article underlines that they show the characteristics of the Kufic script of the Taifa's period in the eastern area of Al-Andalus. It provides two complete dated alphabets. It highlights the role of power on the adoption of its calligraphic model by the people.

Key words: Arabic Epigraphy, Epitaphs, Al-Andalus, Valencia, 11th century.

El interés por las inscripciones árabes es prácticamente nulo en ambientes académicos de dentro y fuera de la Península Ibérica; en parte, porque el texto que ostentan suele ser el epitafio de alguien anodino pero, sobre todo, por la dificultad de interpretarlas y por la falta de especialistas en la materia. La pérdida de tantos materiales que pertenecen a la disciplina "Epigrafía Árabe" -tan escasamente cultivada en España- permite sostener la afirmación, tal vez un tanto exagerada por resumida, de que a las lápidas árabes se las traga la tierra.

Data de recepció: 14 d'abril de 2020 / Data d'acceptació: 24 d'abril de 2020. 
Desde hace años dedico los esfuerzos de mi ya larga trayectoria profesional al estudio sistemático de las inscripciones árabes andalusíes sobre cualquier tipo de materiales, tanto de las halladas en tierras valencianas como de cualquier otra procedencia, e incluso de los escritos espontáneos que llaman grafitos. Durante ese tiempo he intentado fijar los formularios epigráficos empleados en al-Andalus y establecer los usos que caracterizaron sus zonas geográficas y, en función de ellos, facilitar la lectura, localización y data aproximada de las piezas estudiadas (Barceló, 1990; 1998), pero sin pretensión alguna de que el resultado de ese análisis sea una rígida regla matemática y sin ocultar que he cometido algún error, como datar en el siglo XI una inscripción toledana (Barceló, 1990, 52) que lleva grabada la fecha 660 de la Hégira / 1261-1262 de Jesucristo.

El libro de Lévi-Provençal sobre las inscripciones árabes de España recogió muchas que se habían dado a conocer antes de 1931, fecha en la que se publicó la obra fuera de nuestra Península, pero el prestigioso historiador pasó por alto piezas ya conocidas y editadas en su época. Transcurridos casi noventa años, urge incorporar aquéllas y analizar, estudiar y extraer las conclusiones epigráficas e históricas de todos los epígrafes que han ido apareciendo después de los años treinta del siglo pasado; esto permitirá conocer mejor la evolución de la kitāba oficial andalusí, la ideología subyacente en los diferentes momentos históricos de dominio político y los aspectos meramente técnicos de la artesanía andalusí del grabado sobre piedra.

Mientras eso sucede, presento en las líneas que siguen algunas inscripciones de las que he tenido noticia en fechas relativamente recientes, a las que añado otras dadas a conocer con anterioridad. Pienso que cada una de ellas tiene algún matiz que merece nuestro interés, tanto desde un punto de vista epigráfico como histórico y cultural. Han aparecido en la fachada marítima peninsular (Xàtiva, València, Alpuente); otras son de procedencia desconocida y las guarda el Museo de León. Considero, desde mi punto de vista, que su información será de utilidad para el estudio de la Epigrafía andalusí y ayudará a un mejor conocimiento general del pasado islámico peninsular y en particular valenciano.

\section{ALGO MÁS SOBRE LA EPIGRAFÍA DE LAS TAIFAS}

El Levante, conocido en árabe como šarq al-andalus, es un amplio territorio que en el siglo XI, tras el hundimiento del califato de los Omeya, albergó pequeños estados independientes que reciben el nombre de "Taifas", como es de todos sabido. Cada uno de esos lugares tuvo su sede principal en una ciudad, desde la que sus gobernantes regían los destinos de una fluctuante zona de influencia. Así, València, que controló en algún momento Murcia y Almería, 
pasó a ser gobernada por Toledo para, un poco más tarde, ver como El Cid reducía su área de control antes de que la ciudad pasara a manos almorávides. Tortosa, que al principio se declaró autónoma, fue sometida primero a Dénia y después a Zaragoza. Sin embargo, Alpuente, que tuvo un reducido distrito, no fue absorbida por sus potentes vecinos.

Es sabido que Dénia dominó un amplio territorio desde la sierra de Segura a las islas Baleares. La epigrafía producida en esta taifa ha sido objeto de un reciente trabajo monográfico que muestra que casi todas las piezas fueron grabadas en relieve, con alifatos de cúfico simple propios y una letra austera y carente de adornos que poco tienen que ver con el estilo califal cordobés (Barceló, 2016a). El territorio insular y peninsular de la taifa conserva 24 estelas más o menos completas, además de ocho inscripciones desaparecidas que no han dejado tras de sí dibujos y/o fotografías (sólo breve información escrita), de las cuales pertenecen a la capital taifa solo cuatro epígrafes, en tres lápidas de la segunda mitad de la centuria (1066-1092), es decir durante los gobiernos de 'Alī Iqbāl al-dawla (1045-1076) y de los miembros de la dinastía hūdí de Zaragoza al-Muqtadir (1076-1081) y su hijo Mundir (1081-1091).

Todas esas lápidas quedan fuera del objeto del presente estudio, interesado en sus vecinas Xàtiva, València y Alpuente. La ciudad del Túria tiene seis inscripciones (dos desaparecidas) en el período comprendido entre 1012 y 1092 (Barceló, 1998, n. ${ }^{\circ}$ 5, 7, 14, 20, 34, 66), la ciudad de los Borja guarda dos (Barceló, 1998, n. ${ }^{\circ} 12,33$ ) y Alpuente, una sola (Barceló, 1998, n. ${ }^{\circ}$ 17). De la taifa toledana, su capital arroja un monto de más de cuarenta inscripciones funerarias (Gómez Ayllón, 2006) y Almería llega a quince (Ocaña, 1964, n. . 11-25).

El número de inscripciones levantinas es abundante cuando se compara con los escasos testimonios recogidos en otros territorios de importancia en el siglo XI. Salvo las que ostentan elementos arquitectónicos, tienen tan solo tres estelas las ciudades de Sevilla (Lévi-Provençal, 1931, n. ${ }^{\circ}$ 30bis, 31, 32), Murcia (Lévi-Provençal, 1931 , n. ${ }^{\circ}$ 100; Barceló, 1998, n. ${ }^{\circ}$ A2; Pujante, 2008, 322), Zaragoza (Barceló, 2016d, 100) y Badajoz (Martínez Núñez, 2013, n. ${ }^{\circ}$ 2, 3, 5). Ninguna inscripción conservan las capitales de Granada y Málaga.

Aunque los hallazgos se produzcan de forma fortuita y por tanto aleatoria, denotan la existencia en el siglo XI, en determinadas áreas de al-Andalus, de una clara preferencia por las inscripciones, tal vez por estar su población más o mejor arabizada.

\section{EPITAFIO DE LA TAIFA DE XÀTIVA (429/1038)}

Tuve noticia de esta lápida, antes de su ingreso en el Museu de l'Almodí de la ciudad de Xàtiva, gracias al arqueólogo Alex Escrihuela que me proporcionó 
los datos del hallazgo y me facilitó su consulta. Apareció mientras se realizaban obras de seguimiento arqueológico, bajo su dirección, en la primavera de 2004, en una parcela de la partida llamada "La Bola", en la zona urbana colindante por oriente con un área ya excavada hace años. En ambos terrenos se documenta una necrópolis con un uso continuado de varias centurias, sin que hayan aparecido datos arqueológicos anteriores al siglo XI. La pieza, sin embargo, se halló fuera del lugar para el que fue diseñada y sin vínculo alguno con un enterramiento.

Aunque se ignore su exacta extensión, puede identificarse sin ninguna duda con la zona de sepulturas que fuentes árabes de los siglos XII y XIII llaman maqbarat al-rabad o "cementerio del Arrabal", único sitio documentado en la ciudad, aparte de algún panteón de ubicación desconocida (Barceló, 1998, 4647). Al conquistar la villa en el siglo XIII, como lindero en algunas donaciones, Jaume I incluye indicaciones de fosas (Barceló, 1998, 48), que tradicionalmente se sitúan en el área de Les Barreres, donde estuvo la morería hasta la expulsión de los moriscos en 1609.

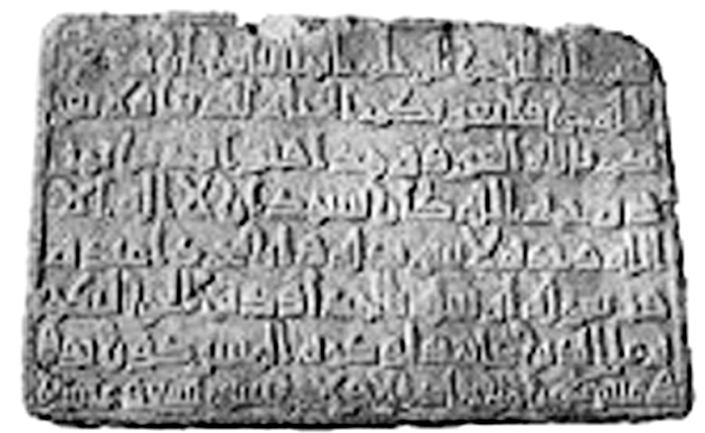

Figura 1. Epitafio de 429/1038. Xàtiva (Museo del Almodí)

El formato de esta pieza es el más frecuente entre los usados en la Península Ibérica, si bien son menos habituales las lápidas cuyo texto se extiende entre los lados más cortos, como sucede en este epitafio. Con estrecho listel bordeando el campo epigráfico, sus medidas coinciden con las que proporcionan otras estelas del siglo XI descubiertas en tierras de al-Andalus y en particular en el territorio valenciano (Barceló, 1998, 66). Dentro de la caja de escritura se ven las marcas dejadas por el puntero del artesano al dar fondo a la superficie del campo epigráfico.

Es importante reseñar que para su labra se usó material marmóreo de la zona setabense, en concreto un fragmento de Buixcarró, reutilizado porque 
parece ser un elemento arquitectónico que podría haber sido romano; en el envés del canto del lado superior conserva varias acanaladuras que podrían haberse practicado con destino, tal vez, a la decoración de una cornisa (Barceló, 2007).

Como se ha podido constatar en repetidas ocasiones, los árabes, a menudo, aprovecharon para grabar sus epígrafes el material romano, bizantino y visigótico, ya trabajado, que estuviera a la vista en ruinas de edificios o que recogían en cementerios. Por ejemplo, en Chella (Rabat, Marruecos) se halló el epitafio del sultán meriní Abū Ya'qūb Yusūf (m. 706/1307), cuya lápida se dio por perdida durante un tiempo (Basset y Lévi-Provençal, 1922, 40-41) y conserva ahora el Musée archéologique de Rabat (N. ${ }^{\circ}$ Inv. 89.5.2.4). Aun conserva en su otra cara una inscripción latina que cita al gobernador de la Bética, A. Caecina Tacitus, lo que indica que la piedra se llevó al otro lado del Estrecho desde al-Andalus.

En estelas andalusíes halladas en diversos lugares de la Península no es raro encontrar reutilizado material marmóreo romano, como en Toledo (Delgado, 1987, n. ${ }^{\circ}$ 70), Mérida (Barceló, 2016c), Portugal (Barceló, 1998, 71), Jaén, cuya iglesia de la Magdalena guarda una estela con epígrafe árabe en una cara y latino en la otra, o Torre de Juan Abad (Ciudad Real), en cuya ermita de Nuestra Señora de la Vega hay una grabada sobre un epitafio romano con el texto latino borrado (Barceló y Labarta, 2019); e incluso se usó piedra calcárea, como en Trujillo, donde se utilizó un ara de época romana (Díaz Esteban, 1987, 175-176, 180-181).

En el oriente de al-Andalus no se conocían epitafios sobre material de otras culturas hasta la aparición en la monumental Sagunt de un reloj de sol, diseñado en el siglo XIII sobre un ara romana de mármol blanco de Carrara (Barceló, 1998, 71 y n. $\left.{ }^{\circ} 47\right)$, y de una estela del siglo X grabada sobre otra ara de mármol rojizo (Barceló, 2001, 169-170). El de Xàtiva es una nueva prueba.

\subsection{El epígrafe}

Edición

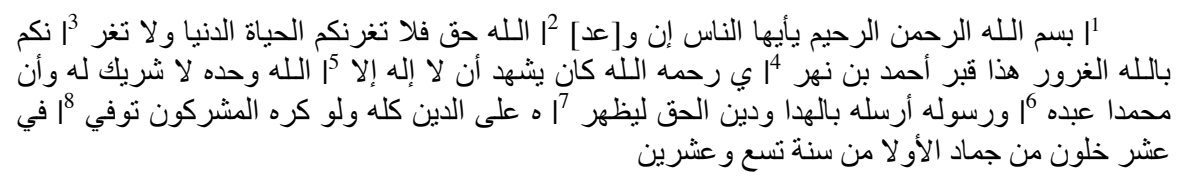


Traducción ${ }^{1}$

En el nombre de Dios, el Clemente, el Misericordioso “¡Hombres! ¡La promesa de Dios es Verdad! 'Que no os seduzca la vida mundanal ni os extravíe respecto de Dios el Seductor!" (Corán XXXV, 5). Ésta es la tumba de Ahmad b. Naharī ¡Dios se apiade de él! Daba testimonio que no hay más divinidad que Dios, Único, que no tiene asociado, y que Mahoma es su servidor y su enviado. Él le ha mandado "con la Dirección y la religión verdadera para que prevalezca sobre todas las religiones, aunque le odien los asociadores" (Corán IX, 33 = LXI, 9). Falleció a diez pasados del primer ŷumāda (sic) del año veintinueve (18, febrero, [10]38).

\subsection{Comentario del texto}

El formulario difiere levemente del que ofrece una lápida del año 422/1031 descubierta en la misma Xàtiva, cuyo cierre de epitafio incluye una cita de la Tradición (hadīt ) y otras azoras coránicas ausentes en la presente inscripción (Barceló, 1998, 145-146, n. ${ }^{\circ}$ 12). Sin embargo, tras la basmala introductoria incluye Q XXXV, 5 que hasta ahora únicamente se había hallado a partir del año 436/1045 en estelas de la taifa valenciana (Barceló, 1998, 83-84).

Respecto al onomástico del difunto, aparece mencionado a la manera que se documenta en los epígrafes andalusíes de provincias de este período, es decir solamente por el nombre propio y la filiación (Barceló, 1998, 79). En cuanto a esta, es seguro que el artesano grabó un nombre al final de la tercera línea, cuya inicial (signo 2i) tanto pudo ser B, T, T, N o Y. Faltó una letra que, sin cabida en el renglón, se grabó en la línea siguiente por ser lícita en la escritura cúfica la partición después de la letra rāa' (Barceló, 1998, 102-103). En lugar de Nahratī de mi primera propuesta (Barceló, 2007), edito Naharī ya que considero que en la línea 4 sólo hay un signo 17a. No excluyo que pudiera leerse Nahirī (e incluso Nahrī, en vez de Naharī), ni que la grafía del epígrafe sea en realidad un nombre sin etimología árabe que no sé interpretar.

\subsection{La epigrafía}

Algunos signos muestran una ligadura por debajo del renglón y otros, un ápice o remate ascendente (forma llamada "cuello de cisne") que sitúan esta

1 A partir de aquí uso, sin citarla, la traducción del Alcorán de Vernet (1963) o de Cortés (1980) que mejor se adapte al desarrollo del texto en la lápida.

Saitabi. Revista de la Facultat de Geografia i Història, 70 (2020), pp. 179-207

ISSN 0210-9980 DOI: 10.7203/saitabi.70.15553 (c)(1) () 
modalidad de letra cúfica en el primer tercio del siglo XI (Fig. 2). No obstante, el alifato se aleja un poco del que exhibe otra estela hallada en la misma Xàtiva datada siete años antes, en 422/1031 (Barceló, 1998, 145-146, n. ${ }^{\circ}$ 12). El tallista siguió el estilo y el formulario heredados de los empleados por el poder de Córdoba al final del siglo X, durante el período de mando de Almanzor, hāâyib (978-1002) del califa Hišām II, y de sus descendientes; pero el módulo de las letras cordobesas, coeficiente de alif 1:5 (Barceló, 2013, 171), no coincide con el de la lápida setabense, mucho más pequeño $(1: 2,7)$.

El mayor parecido del alfabeto y formulario usados en nuestro epígrafe está en València bajo gobierno del nieto del citado Almanzor, 'Abd al-'Azīz (1022-1060), con título honorífico homónimo y mandatario en la taifa, a la que perteneció Xàtiva desde el momento de su proclamación (Barceló, 1998, 8284, n. $^{\circ} 12$ y 14). Además de en monedas de los años 412 a 446/1021-1054 emitidas a nombre de dicho 'Abd al-'Azīz (Prieto, 1926, 182-185, lám. 6), ya se pueden observar signos parecidos, con coeficiente 1:3, en una inscripción procedente de la ciudad de València fechada en 425/1034 (Barceló, 1998, n. ${ }^{\circ}$ 14, lám. XIII).

Desde el punto de vista gramatical, el ductus árabe es bastante correcto, pero el artesano grabó el nombre del mes lunar con scriptio defectiva ( $\hat{y} u m \bar{a} d a)$ y su adjetivo femenino con alif mamdūda $(a l-\bar{u} l \bar{a})$. Aunque a primera vista la factura de la lápida parece en general correcta, sospecho que quien diseñó el epitafio aún no era maestro en este oficio pues la línea-base no mantiene una distancia regular, como delata sobre todo la última en la que el grabador tampoco dejó espacio para incluir la fecha completa del óbito, que en esta época y zona concluía el epitafio. Además, las letras de la última línea son de menor tamaño y, aunque están muy apretadas, la última palabra (que contiene una cifra) no pudo ser tallada completa y se tuvo que dividir; por eso, para incluir los dos signos que faltaban, se usó la interlínea superior ( $i \check{i s ̌} / \overline{\mathbf{t}} n$ ).

De ello resulta que en la inscripción sólo figure la palabra 'veintinueve', faltando en el epígrafe la centena de la data islámica. Cuando la prensa publicó la noticia de su hallazgo, esta anomalía dio pie a fantásticas elucubraciones sobre la antigüedad de la inscripción en un blog de la Web (Manzano, 2005) y se aseguró que era anterior a la conquista islámica de la Península Ibérica (año 29 Hégira / 649-650 JC).

Esos errores de labra y la forma defectuosa de trazar los signos se aprecian también en la primera línea, en la que el artesano unió letras que deben separarse; dio al trazo 2i de al-rahīm un diseño anómalo y desproporcionado, que por su mayor altura semeja $12 \mathrm{i}$; y aún se aprecia al final del primer renglón $l h$, resto de la voz Alläh que borró y trazó correctamente al principio de la segunda línea, tal vez porque calculó mal y no cabía. Tuvo que grabar la letra $r \bar{a}$ ’ sobre 


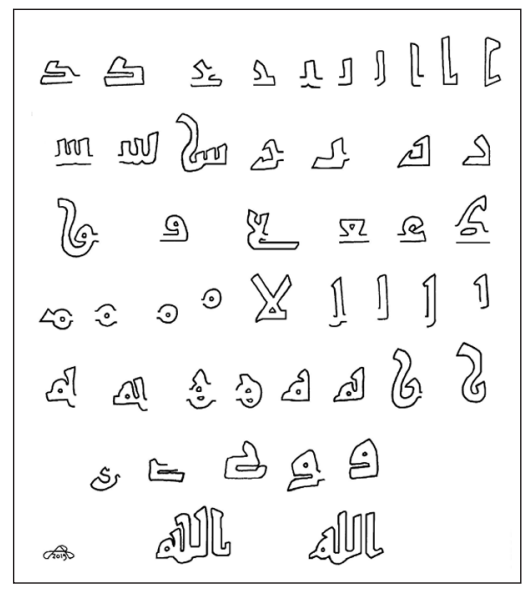

Figura 2. Alifato cúfico de 429/1038. Xàtiva (Dibujo de C. Barceló).

el marco de la línea 6 por falta de espacio (li-yaz̧hura) y, en vez de jalawna, cometió otro error de labra (>ylwn<) en el último renglón que corrigió al grabar la correcta traza $3 \mathrm{i}$ en la interlínea. Con todo, la lápida setabense facilita un alifato fechado de la inscripción (Fig. 2).

\section{EPÍGRAFE ÁRABE EN LEÓN}

Gracias a la amabilidad de la doctora Ana Labarta, que me ha facilitado fotografías de los epígrafes leoneses y la información que atentamente le dio don Manuel Antonio García Garrido, técnico del Museo de León, he sabido de esta inscripción.

El Museo de León, que conserva algunos interesantes objetos de época andalusí (Grau Lobo, 1993, n. ${ }^{\circ}$ 57, 109-110; Gómez Moreno, 1925, I, 177 y II, lám. 155-156), posee desde 2006 este fragmento de estela de mármol, obsequio de don Felipe Carlos Martínez Prieto, presidente ese mismo año de la Asociación de libreros de viejo y antiguo de Castilla y León. El donante dice que adquirió la lápida en la capital, junto con un lote de libros. Si bien pudiera proceder de la Montaña leonesa, no existe certeza sobre su origen; más aún si se tiene en cuenta que en enero del año de la donación el librero adquiría en Madrid una biblioteca privada importante, aunque esto tampoco añade seguridad sobre la anterior ubicación de la piedra. 
Me ha sido imposible verificar en todos sus extremos una noticia que sugiere que en la Vega de Boñar hubo una inscripción árabe que se habría hallado en la plaza de San Ignacio, en el edificio del Alfolí que fue derribado a finales de los años noventa del siglo pasado. Cabe preguntarse si sería este fragmento la lápida que según dicen conservaba dicho edificio; o si tal vez el verdadero origen de la pieza sería otro lugar alejado de las tierras leonesas. En este lugar, que forma parte del municipio de Boñar, apareció otro fragmento con inscripción árabe a mediados del siglo XIX (cf. § 3).

Al menos uno de esos dos epígrafes, si no ambos, es posible que se trasladara a la Montaña leonesa. Se trataría de dos muestras más de los viajes que tantas inscripciones árabes andalusíes han hecho a lo largo de los siglos. Sólo en nuestra Península basta recordar la pila califal cordobesa que guarda la catedral de Santander (García Gómez, 1947, 155-161). Hay constancia de que piedras marmóreas de túmulos islámicos fueron a parar al Rosellón francés después del ataque genovés-catalán de 1146 a Almería; al igual que tras el asalto italo-catalán a la isla de Mallorca en 1115 el epitafio de al-Murtadà se trasladó a Pisa y se observa un proceder similar, practicado por los habitantes de poblaciones costeras del Levante peninsular pero en sentido inverso, al transportar a la Península lápidas árabes de poblaciones norteafricanas mediterráneas (Barceló, 2015, 178-179 y 190-191).

a)



b)

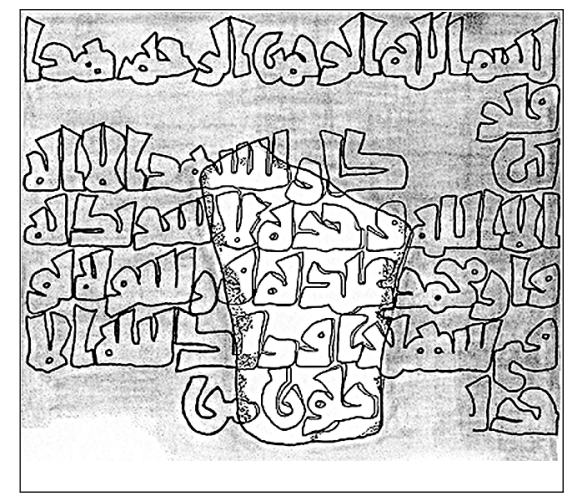

Figura 3. a) Fragmento de estela del siglo XI; b) Restitución del epígrafe (Foto: Museo de León. N. ${ }^{\circ}$ Inv. 2006/35; dibujo de C. Barceló).

Entre las granadinas "viajeras" (Ríos, 1883, 239-240) está el epitafio de Yūsuf III, hallado en Santa María del Azogue (Betanzos, A Coruña); del panteón o Rawda de los sultanes nazaríes fueron a parar otros dos al convento de 
Madres Concepcionistas Franciscanas de Torrijos (Toledo); el de un Abencerraje se descubrió en la casa señorial de Alcalá la Real (Labarta, 1992); de dos personajes nazaríes con el título al-wazì $r$, un fragmento se halló en la ermita de São Tomé de Aguiã de Arcos de Valdevez (Braga, Portugal) (Labarta, 2015, 219-221) y el otro, recogido en una colección extremeña, lleva un pequeño poema funerario (Barceló, 2016b, 44-55).

He procedido a una restauración del texto hasta donde ha sido posible (Fig. 3b). Por ello se puede atribuir a la estela completa un campo epigráfico con un ancho de unos $420 \mathrm{~mm}$. Respecto a la altura, se alzaría unos $500 \mathrm{~mm}$ aproximadamente porque el epígrafe tendría cinco líneas más: tres antes de la primera actual (basmala, $h \bar{a} \underline{d} \bar{a}$ qabr y onomástico) y dos después de la última (mes y año). A estas medidas hipotéticas habría que añadir las del recuadro de reserva que tenían las inscripciones de al-Andalus, de unos $15 \mathrm{~mm}$. La estela gozó de un filete de enmarque cuya medida no se puede calcular ya que se trata de un resto del centro de la losa de mármol.

\subsection{El epígrafe}

Edición

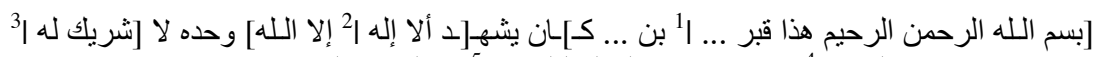

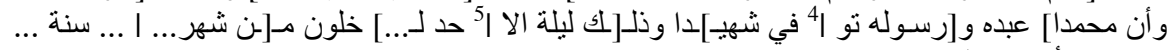

و و وان مين وأربع مائة

\section{Traducción}

[En el nombre de Dios, el Clemente, el Misericordioso. Ésta es la tumba de ... b. ... Él da]ba testi[monio que no hay más divinidad que Dios,] Único, $\sin$ [asociado y que Mahoma] es su siervo y [su enviado. Falleció márt]ir y es [o la noche del domingo a... días] pasados de [1 mes... año... y cuatrocientos].

\subsection{Comentario del texto}

A simple vista y sin más análisis, el texto de este pequeño trozo de mármol parece coincidir con el de otro fragmento que conserva el Museo de León (cf. § 3), que podría completar. Sin embargo, fallan todos los intentos para acoplarlos, de modo que hay que concluir que son partes de dos epitafios distintos, aunque ambos responden al alifato de un taller de cronología próxima, pero con variantes significativas. De los escasos restos de texto de la inscripción de 
este fragmento poco se puede obtener sobre la fecha del óbito, salvo que la defunción tuvo lugar entre el tres y el diez (jalawna) del mes en que se produjo (tal vez domingo o martes) y que la inscripción mencionó la muerte de un

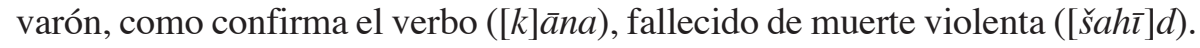

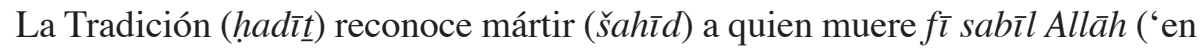
la senda de Dios'), circunstancia que en Occidente sólo se relaciona con la "guerra 'santa"'. Pero el martirio puede alcanzarse por otros incidentes: la peste, un derrumbe, una diarrea o ahogarse. A esto dedicó el investigador francés William Marçais (1900) unas páginas a propósito de la peste de 1819 en la argelina Tremecén. Aquí la causa del fallecimiento figura después del testimonio completo de fe islámica ( $\breve{a} a h \bar{a} d a)$ en vez de antepuesto al onomástico como se aprecia en otros epitafios andalusíes (Barceló, 1990, 48).

El formulario que ostenta la presente inscripción, formado por šahāda, causa de muerte y fecha, coincide con lápidas del siglo XI de Murcia, Toledo y Granada (Barceló, 1990, 46-47). Pero esa secuencia final sólo es igual a la que exhiben piezas funerarias toledanas fechadas antes del año 423/1032, durante el gobierno sobre la taifa de Ismā‘̄il al-Zāafir (m. 435/1043). La estructura del texto de esta pieza de León ya no se empleará sobre lápidas de décadas posteriores en Toledo (Barceló, 1990, 47), pues o bien no se menciona en ellas la šahāda en esa posición o se coloca después de dar la fecha del óbito (Gómez, 2006, I, 4.2.2.6).

\subsection{Comentario epigráfico}

Los caracteres cúficos de esta lápida tienen paralelos casi exactos en alifatos producidos a nombre de Ismā'îl al-Zāafir en su primera etapa de gobierno en Toledo a partir de 421/1030, a pesar de que los historiadores vengan considerando válida la noticia dada por Ibn al-Jațīb (1313-1375) de que el primero de los D̄ū-l-Nūn comenzó a gobernar en el año 427/1035-1036, una evidente errata del editor o los copistas por la fecha 417/1026.

En cuanto al alifato, el de este fragmento de León y los de la capital imperial, datados entre los años 420/1030 y 440/1050, coinciden en: conceder cierta redondez a los caracteres $15 \mathrm{i}$ y $15 \mathrm{~m}$; un diseño del signo 4 sin apenas ápice vertical; compartir la igualdad dada en altura a todos los trazos; y un coeficiente bajo de proporcionalidad en la letra alif (1:2,7). Esa escasa proporción, que en el fragmento es también 1:2,7, produce un alifato de aspecto arcaico, con formas tan compactas e inconfundibles que sería preciso remontarse a la etapa emiral para encontrar otras como éstas. Recordaré que la lápida setabense comparte este pequeño coeficiente y data (cf. § 1). 
La inscripción conservada en la institución leonesa tiene paralelos con otras muestras de la epigrafía oficial de la taifa toledana (Lévi-Provençal, 1931, n. ${ }^{\circ}$ 57, 58, 60): dos brocales de pozo de 423/1032 y 429/1038 y una lápida conmemorativa (432/1041). Existen dos paralelos más, casi exactos, en otras tres estelas mortuorias de la misma procedencia: dos datadas en 421/1030 y otra en 426/1035 (Lévi-Provençal, 1931, n. ${ }^{\circ}$ 55; Ocaña, 1954, n. ${ }^{\circ} 2$ y 3). Puede afirmarse, por tanto, que este fragmento formó parte de una lápida producida en Toledo bajo el gobierno de al-Ẓāfir, antes de que le sucediera en el cargo su hijo al-Ma'mūn (1044-1075).

\section{INSCRIPCIÓN ÁRABE EN LEÓN ( \pm 440-460/1048-1068)}

Hace bastante tiempo que el Museo de León exhibe un fragmento de mármol con un epígrafe de cinco líneas en letra árabe (Gómez Moreno, 1925, I, 171-172 y II, lám. 159; Grau Lobo, 1993, 102-103, lám. 53b). Procedía de un rescate realizado en la localidad de Vega de Boñar, según consta desde hace tiempo. Este lugar, que forma parte del municipio de Boñar (antigua calda romana como descubre el topónimo), se halla en los confines de los Picos de Europa con Asturias, a pocos kilómetros del pantano de Porma y unos 50 de la capital provincial.

El fragmento que custodia el Museo de León se encontraba depositado a finales del siglo XIX en el Seminario Conciliar de León, donde Ríos lo vio y la publicó, sugiriendo su procedencia foránea y dando lectura y traducción correctas (Ríos, 1883, 238-240). Puede suponerse, a tenor de la institución que la custodiaba, que el mármol llegó a la capital leonesa como consecuencia de la desamortización eclesiástica de Mendizábal (1834-1854), en una época en que se redujo a un tercio el número de monasterios y conventos; esto sería más problable que suponer que ingresó en el Seminario procedente de la desamortización que promulgaron las Cortes de Cádiz (1823).

Desde hace años esta muestra epigráfica árabe, a la que se debe unir la que custodia la misma institución leonesa (cf. § 2), ha llevado a la sospecha de una procedencia extraña a la zona pues se localizó en tierras tan alejadas de los musulmanes. En 1906 Gómez Moreno, que conoció y describió esta lápida en su conocido Catálogo, añadió a lo ya sabido sobre la inscripción que el envés se había empleado como losa (Gómez Moreno, 1925, I, 171-172).

Extrañó a Ríos que el epígrafe árabe estuviera en la Montaña y apuntaba que "debió ser como trofeo de victoria llevado alli”". Igual opinó Gómez Moreno, que lo dató en el siglo $\mathrm{X}$ y sostuvo que en aquella zona era "en absoluto inverosímil que se hiciese", y añadía: "del Tajo para arriba nada conozco equi- 
parable. Probablemente se llevaría, en tiempo más o menos lejano, desde Toledo o Andalucía, para utilizar el mármol" (Gómez Moreno, 1925, I, 172). En efecto, la inscripción tiene todas las características del cúfico practicado en la taifa toledana a mediados del siglo XI, como ya propuso Ríos (Ríos, 1883, 239).

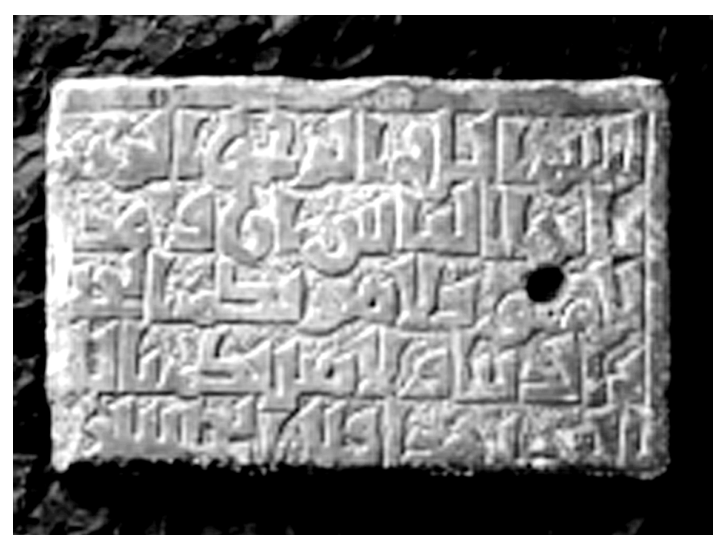

Figura 4. Inscripción toledana del siglo XI (Museo de León. N. ${ }^{\circ}$ Inv. 508/2824).

Aunque ya era conocida en el siglo XIX, la bibliografía que trata de las inscripciones árabes peninsulares y toledanas de época islámica la ha ignorado. Ni Lévi-Provençal (1931) la recoge, ni la cita Zozaya (1990) en su estudio de un epígrafe de Calatrava la Vieja y también falta en el inventario de Rosselló (1998) y en el estudio de Gómez (2006).

\subsection{El epígrafe}

Edición

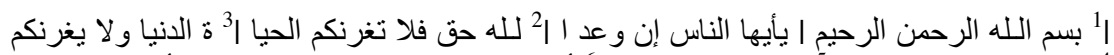

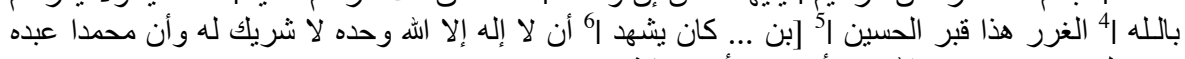

$$
\begin{aligned}
& \text { ورسوله ... توفي رحمه الله ... و واربعين وأربع مائة] }
\end{aligned}
$$

\section{Traducción}

En el nombre de Dios, el Clemente, el Misericordioso “ ¡Hombres! La promesa de Dios es verídica. ¿Que no os extravie la vida mundanal ni os extravíe, respecto de Dios, el seductor!" (Corán XXXV, 5). Ésta es la tumba de 
al-Husayn [b. ... Daba testimonio que no hay más divinidad que Dios, Único, sin asociado, y que Mahoma es su siervo y su enviado.... Falleció ¡tenga Dios misericordia de él! ... cuarenta y cuatrocientos].

\subsection{Comentario del texto}

Respecto a la posible vinculación toledana antes señalada, coincide el epígrafe con la formulación seguida de basmala y Corán XXXV, 5, presente en once epitafios de ese origen a partir de 443/1052 (Gómez, 2006, 4.2.2.5). He reconstruido šahăda porque sigo la estructura conservada en los textos de doce estelas toledanas que, entre el onomástico y la fecha del óbito, la incluyen completa entre los años 447-468/1055-1075 (Lévi-Provençal, 1931, n. ${ }^{\circ}$ 62-65; Gómez, 2006, 4.2.2.3), período que coincide con el gobierno sobre la taifa del $\underline{d} \bar{u}-l-n \bar{u} n i ́$ al-Ma'mūn (1044-1075). No obstante, la estructura de nuestro epitafio ya no coincide con la mostrada en las lápidas de la taifa de Toledo en décadas posteriores al año 470/1077, esto es en la etapa que al mando de la taifa estuvo el último gobernante de la dinastía, Yahyyà al-Qādir (1075-1085). Se puede concluir, pues, que este epígrafe conservado en el Museo de León tiene un origen toledano, probablemente de su capital, y que la cronología que se puede atribuir al texto que recoge el fragmento se inscribe entre 440/1048 y 460/1068.

En cuanto al onomástico del difunto, en estelas toledanas de esos años es frecuente que el individuo se cite sólo por nombre y filiación, lo que sugiere que en la línea siguiente figuró este extremo, es decir el nombre del padre o antepasado; luego le seguiría, antes de la fecha, la profesión de fe de los musulmanes. Por desgracia, poco informa que el nombre sea al-Husayn, aunque sirva para dilucidar preferencias onomásticas en la mencionada ciudad durante este período. Con todo, la nómina de sabios de la taifa toledana recoge dos individuos con el mismo nombre: (al-)Husayn b. Walīd b. Nașr (m. 390) y al-Ḥusayn b. al-Ḥasan b. Aḥmad Ibn al-Fatḥ (m. 473) (Ávila, 1990, n. ${ }^{\circ} 264$; Guardiola, 1990, n. ${ }^{\circ} 353$; Ávila y Marín, 1995, n. ${ }^{\circ} 469$ ).

\subsection{La epigrafía}

A la buena factura de la labra en este mármol sólo se podría afear la licencia del artesano al grabar en la línea 5 al-gurur, con scriptio defectiva, esto es sin la traza 16a que acompaña a esta palabra en el texto canónico del Corán (algurür). Como sucede tantas veces observando la técnica de labra, en la superficie del campo epigráfico del mármol leonés se ven las marcas que dejó el 
artesano al trabajar el fondo de las letras con el puntero (Fig. 4). Ese modo de trabajar señala un taller de la ciudad de Toledo del que salieron otros ejemplares epigrafiados: epitafios de Aḥmad b. Sa 'īd al-Bațalyawsī (m. 27 raŷab 441/27 diciembre 1049), del alfaquí Abū 'Uțmān Sa'īd Ibn Ŷa'far (m. 20 ramadān 443/25 enero 1052) y de una mujer, Hind, hija del wazīr Bušrà b. Fā'iq, que no conserva fecha (Gómez, 2006, n. ${ }^{\circ} 19,22,23$ ).

Respecto a la apuntada posible vinculación toledana, el alifato de la pieza de León tiene paralelos exactos en lápidas de aquella procedencia, fechadas o datadas en la cuarta década de la quinta centuria islámica, es decir a mediados del siglo XI (Delgado, 1987, n. ${ }^{\circ}$ 58, 59, 63, 72, 73, 79, 89; Lévi-Provençal, $1934,147-149$, n. $^{\circ} 1$ [= 1931, n. ${ }^{\circ} 65$ bis] $)$. En concreto, los que presentan rasgos epigráficos más parecidos con este fragmento son cipos y estelas de la ciudad imperial datados entre 441/1049 y 449/1058 (Delgado, 1987, n. ${ }^{\circ}$ 58, 72, 73, 75, 76; Lévi-Provençal, 1931, n. ${ }^{\circ}$ 61, 69; Gómez, 2006, n. ${ }^{\circ}$ 19, 22, 29, 31, 32).

\section{LA LAUDA DE 'IZZ AL-DAWLA DE ALPUENTE}

Este pequeño trozo de mármol grisáceo se halló por casualidad en la villa valenciana de Alpuente. Apareció al final de los años noventa del siglo pasado como material de relleno del muro interior de una vivienda, durante las obras de reforma hechas en una finca situada en la parte exterior de las murallas y frente a la actual "Casa ayuntamiento". Debo esta noticia a la amabilidad de doña Amparo Rodríguez Sambonet, alcaldesa de Alpuente entre 1999 y 2015.

No he podido ver la inscripción porque es propiedad de un particular cuya identidad desconozco, pero para su estudio me he servido de una fotografía que ilustró un artículo sobre el municipio en 2001 y de otras hechas para una exposición que se habría de celebrar en Granada en 2018 sobre "La Granada zirí y el universo bereber". Agradezco datos y copia de dichas fotografías a la arqueóloga Cristina Albir Herrero.

El fragmento, que tiene cuatro líneas con restos de letras, pertenece al centro de la parte inferior de una lápida; así lo acredita la banda o listel que remata la piedra al pie de la inscripción (Fig. 5a). Sin que pueda ser considerada una coincidencia fortuita, la forma de las fracturas de esta piedra casa a la perfección con la de las roturas de una lápida funeraria hallada en Alpuente, también fracturada con pérdida de varias líneas de texto del cuerpo inferior (Barceló, 1998, n. ${ }^{\circ}$ 17). Si esto no fuera suficiente prueba de que esta pieza se desprendió de la otra, el tipo de caligrafía empleado en esa lauda es idéntico al modelo y tipo de letra del presente fragmento y además, el texto que ostenta este trozo 
de inscripción habría figurado en los desaparecidos últimos renglones del otro epitafio de Alpuente que se guarda desde el siglo XIX en València, donde se expone en una pequeña sala dedicada al pasado islámico valenciano del MBA (Fig. 5b).

\subsection{El epígrafe}

\section{Edición}

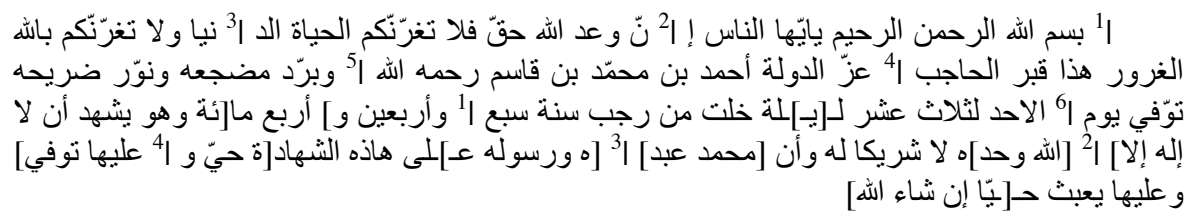

Traducción del fragmento

[... y cuarenta y] cuatrocientos [dando testimonio que no hay más divinidad que Dios, Úni]co, que no tiene asociado y que Mahoma [es siervo suyo y su enviado]. En esta confesi [ón vivió, en ella mu]rió y en ella "será devuelto a la $v i[$ da" (Corán XIX, 15), si Dios quiere].

\subsection{Comentario del texto}

El epígrafe completa la palabra "cuatrocientos" que falta en la línea 7 del fragmento del epitafio del tercer Qāsimī, conservado en el MBA; concluye con dos líneas finales de la estela que hasta ahora no habían sido restituidas y coincide con lo reconstruido de la línea 8 (Barceló, 1998, 153 n. ${ }^{\circ}$ 17, lám. XVIIa). Aunque incompleta, la inscripción de esta pieza permite la recuperación del epitafio, incluso de la palabra "cuarenta" de la fecha, a pesar de que esté ausente en ambos fragmentos. Debo advertir que cuando restauré el octavo renglón de la lauda no podía prever un error del artesano, que grabó šarīka por el correcto $\check{s}$ arīk. Aun cometió otro error pues, si bien en epígrafes de al-Andalus fue frecuente omitir el signo alif de la marca de acusativo de Muhammad ${ }^{a n}$, esa misma línea 8 solo conserva Muhammad (Barceló, 1998, 109). Desde el punto de vista de la pericia del artesano puede decirse que no era un buen maestro.

A lo que parece, la estela del mandatario de Alpuente era prácticamente cuadrada pues debió medir $445 \mathrm{~mm}$ de altura x $420 \mathrm{~mm}$ de ancho, con una caja de escritura de $375 \mathrm{~mm}$ de altura x $380 \mathrm{~mm}$ de latitud. Con la incorporación 
a)

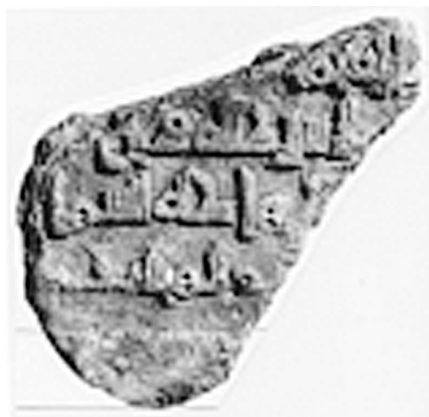

b)

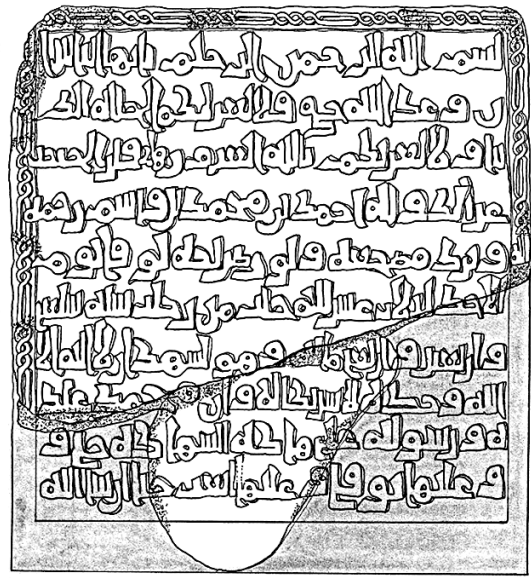

Figura 5. a) Pieza de Alpuente (Fotografía: Cristina Albir); b) Epitafio de 'Izza al-dawla de Alpuente (Dibujo del autor).

del nuevo fragmento, ofrece, además, un alfabeto bien fechado. El texto completo del epitafio dice (Fig. 5b):

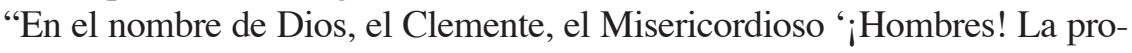
mesa de Dios es verídica ¿Que no os extravíe la vida mundanal, ni respecto a Dios, os extravíe el Seductor!' (Corán XXXV, 5). Ésta es la tumba del hậŷib, 'Izz al-dawla, Aḥmad b. Muḥammad b. Qāsim ¡Apiádese de él Dios, refresque su lugar de reposo e ilumine su última morada! Falleció el diurno del domingo, a trece noches por pasar de raŷab del año cuatrocientos cuarenta y siete (8, octubre, 1055), dando testimonio que no hay más divinidad que Dios, Único, que no tiene asociado y que Mahoma es su siervo y su enviado. En esta confesión vivió, en ella murió y en ella 'será devuelto a la vida' (Corán XIX, 15), si Dios quiere".

Puedo añadir a los datos aportados en su momento (Barceló, 1998, 153156) que el fragmento conservado en el MBA fue un regalo hecho en 1872 a la Sociedad Arqueológica Valenciana (SAV) por Juan Vengud, uno de sus socios fundadores, y por Carlos García, ambos padres de la orden de los Escolapios. La noticia que recoge la memoria de dicha sociedad cultural dice textualmente "Lápida árabe de Alpuente, (provincia de Valencia): época entre los Omeyas y principio de los Almorávides: siglo V de la egira" (Memoria, 1873, 40). La SAV gestionó con la Comisión Provincial de Monumentos, a través del ingeniero José Vilanova Piera (1836-1884), la posibilidad de depositar en el entonces Museo Provincial las lápidas y otros objetos arqueológicos que 
poseía, sin renunciar a la propiedad de los mismos. En dicho museo la vio Rodrigo Amador de los Ríos entre 1875 y 1876, durante la comisión epigráfica que llevó a cabo por España, afirmando que era la única inscripción árabe de que disponía el centro (Ríos, 1883, 216-217).

\subsection{La restitución epigráfica}

En otro lugar he propuesto usar en los estudios andalusíes el mismo método practicado por los epigrafistas de la Roma clásica (Barceló, 1998, 21). A partir de las frases y textos religiosos presentes en un epitafio y del orden en que aparecen (que, como es sabido, según la época sigue modas diferentes), puede integrarse en la inscripción alguna de las palabras o de las expresiones que falten en el epígrafe. Esto deberá hacerse en la edición crítica teniendo presente la parte gráfica, cuya restitución debe seguir el alifato usado en el texto y tener en cuenta las medidas de la piedra. En este caso, el alfabeto está casi completo (Fig. 6).

Algunos colegas me han manifestado su escepticismo, declarándose contrarios a "rehacer" el texto desaparecido. Sin embargo, este fragmento viene a confirmar mi tesis. La aparición de este nueva pieza del epitafio del ḩâŷib Ahmmad b. Muḥammad Ibn Qāsim, conocido en las crónicas por el título honorífico de 'Izz al-dawla, viene a corroborar que la restitución hecha en 1998 era correcta y a confirmar que las palabras que faltaban estaban en los espacios en que las coloqué.

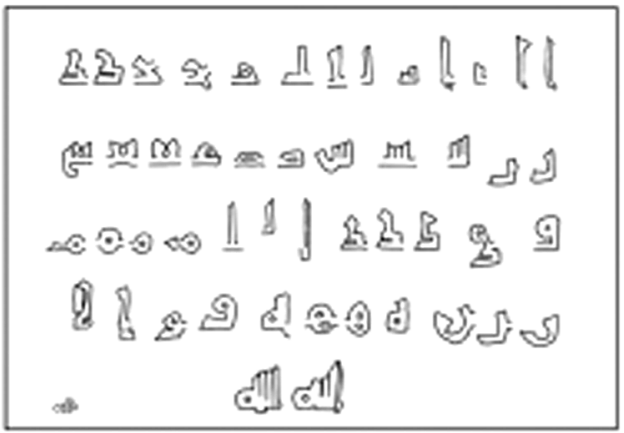

Figura 6. Alifato cúfico de 447/1055. Alpuente (Dibujo de C. Barceló). 


\section{ZÓCALO FUNERARIO VALENCIANO}

Debo los datos e imágenes de esta inscripción a los arqueólogos Joan Vicent Lerma y Pau Armengol, a quienes agradezco su amabilidad. Se halló en València alrededor del año 2006 en excavaciones dirigidas por Aquilino Gallego Úbeda en el edificio n. ${ }^{\circ} 11$ de la calle Pintor Fillol. La vivienda se ubica en el barrio bajomedieval de Blanquerías, una tradicional zona artesanal en la que se ha podido excavar un área cementerial islámica de cierta importancia, según se deduce del número de sepulturas y enterramientos detectados. Se halla la calle junto al distrito extramuros que el Llibre del Repartiment nombra Alfalaga, luego bautizado Tossal, donde los andalusíes tundían paños (al-halaqa) al otro lado de la muralla (Pascual, Martí, 2002, 294 plano 1 y 298 plano 3).

Si la faja que contiene la escritura hubiera formado parte del zócalo de una vivienda, mediría más de $40 \mathrm{~mm}$ de altura como se comprueba al compararla con los 75 y $80 \mathrm{~mm}$ de los revestimientos de mármol hallados en casas de Granada y Málaga (Ocaña, 1945, 165-166). Así pues, estamos ante el fragmento de un zócalo funerario que recibe el nombre de tabica, porque funcionaba igual que el plano vertical de un peldaño o que la tablilla con que se cubre un hueco en una construcción. Era una pieza que revestía la parte baja de la sepultura; sobre ella descansaba la losa que recibía el túmulo llamado maqbariyya (en vulgar, sanām).

Confirmaría ese destino mortuorio del presente fragmento la muesca que presenta en el lado superior, que serviría para encastrar o encajar la losa o cubierta. La pequeña banda que se dejó sin epigrafía en el lateral derecho indica que en ese punto el zócalo formaba ángulo (que sería de $90^{\circ}$ ) con otra pared contigua de las cuatro que formaban el soporte de la losa.

\subsection{El epígrafe}

Edición

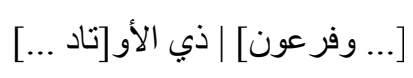

Traducción

"[y con Faraón,] el de las estacas" (Corán LXXXIX, 10). 


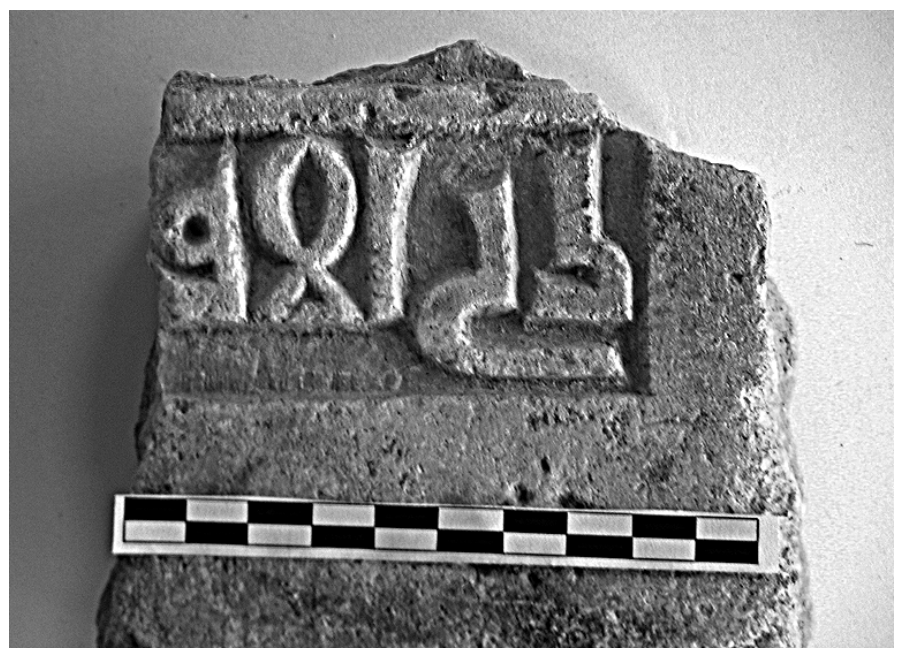

Figura 7. Fragmento de zócalo funerario. València (SIAM 1/803. Foto: Pau Armengol).

\subsection{Comentario del texto}

Nada más que dos veces dedica el Corán el apodo awtād 'el de las estacas, cepos o potros' a Faraón. Este nombre va ligado al de varios pueblos anteriores al Islam y evoca la imagen del más cruel tirano. Sale por primera vez en la aleya XXXVIII, 12: "antes de ellos, otros desmintieron: el pueblo de Noé, los editas y Faraón, el de las estacas" (Cortés, 1980). El texto de este fragmento, sin embargo, es el que parece en las aleyas 6 a 10 de la azora LXXXIX, llamada «La aurora», que comienza con varios juramentos y luego dice: “¿No has visto lo que hizo tu Señor con los ad, con Iram, la de las columnas, pueblo como no se creó igual en ningún país; con tamud, que excavaron la roca en el valle; con el Faraón, dueño de los potros?" (Vernet, 1963). Teólogos musulmanes, como al-Gazālī, comparan a Faraón con Iblīs, es decir el diablo; ambos sufren en el infierno el castigo del fuego eterno porque pretendieron arrogarse la divinidad y se rebelaron contra Dios. Faraón, como Namrod, es considerado en el Islam un prototipo del orgullo y la soberbia.

El término árabe $a w t \bar{d} d$ alude a las estacas o cepos donde se atan los vientos de las tiendas de campaña. Los comentaristas del Corán ven en esta expresión una metáfora que compara al personaje resaltando la idea de "poderoso", "alguien arraigado en el poder", e incluso una alusión a quien dispone y hace uso del tormento del potro pues ven en las estacas una alusión a las que Faraón 
solía sujetar a sus víctimas, de pies y manos, para torturarlas. Otros interpretan que por estacas habría que entender los 'soldados' con que consolidaba su reino. En el Midrás llaman estacas del mundo a los patriarcas, e incluso se estarían refiriendo a los grandes edificios que, a centenares, hizo construir el personaje (Cortés, 1980, 542, n. 12).

El texto coránico, no documentado hasta ahora en la epigrafía funeraria, debió correr por la tabica de la sepultura, aunque sería aventurado decidir dónde comenzaba y acababa la mención; sin que se pueda descartar que se trataba de una alusión contenida en algún poema fúnebre o elegía dedicada al difunto.

\subsection{La epigrafía}

Hay paralelos de este tipo de piezas en otras zonas peninsulares, como Almería y Murcia, en las que se han hallado fragmentos de tabicas con una caja de escritura de altura similar a esta valenciana, es decir 50-60 mm, aunque existe un ejemplar de $80 \mathrm{~mm}$ (Ocaña, 1964, n. ${ }^{\circ}$ 42, lám. 18c). Las almerienses se han datado en el primer tercio del siglo VI/XII (Ocaña, 1968, n. ${ }^{\circ} 31,38,39$ lám. 14a, 17b,c), cronología que se aviene con una pieza descubierta en Murcia (Pujante, 2008), cuyo texto permanece inédito. En todas se usó un tipo cúfico parecido al que se ha encontrado en València.

Sin embargo, aunque la escritura del zócalo brinda pocos signos (Fig. 7), el nexo lām-alif basta para determinar su data ya que en tierras valencianas es característico de la etapa de las taifas. Las grafías del epígrafe son, además, muy parecidas a las del alfabeto cúfico del epitafio de un miembro de la familia Sīd Būna, fallecido en València en 453/1061 (Barceló, 1998, n. ${ }^{\circ}$ 20; Barceló, 2006, 64 fig. 2), se ve en un dirhem fechado en 455/1063 (Prieto, 1926, lám. 6, 164) y guarda similitud con el cúfico de monedas y epitafios toledanos de la etapa de su príncipe al-Ma'mūn, que gobernó sobre Toledo y València en el decenio 457-467/1065-1075.

\section{INSCRIPCIÓN DE VALÈNCIA}

Tuve noticia, acceso a la pieza y calco de la inscripción, antes de ser depositada en el MPDV, gracias a la amabilidad de Joan Vicent Lerma, arqueólogo del SIAM del ayuntamiento valenciano. Se halló en noviembre de 1999 en el transcurso de una excavación que, bajo la dirección del arqueólogo J. Burriel, se efectuó en un solar localizado en València, en el cruce de las calles de Baix y Portal de Valldigna. Salió entre materiales de relleno y fuera de contexto funerario, pero puede sospecharse que proceda del vecino cementerio islámico medieval, al que se accedía por lugar próximo al solar excavado. Sitúan las 
fuentes árabes al oeste de la ciudad una gran necrópolis, a la salida de la puerta llamada de la Serpiente ( $b \bar{a} b$ al-Hanaš), en terrenos del actual barrio de Roters (Barceló, 1998, 44-45).

a)

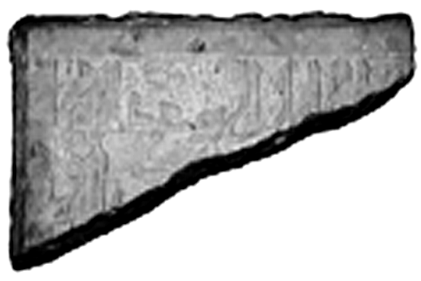

b)

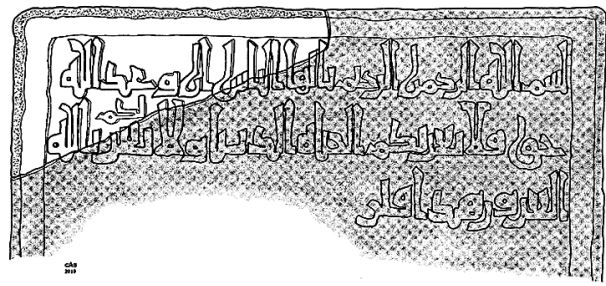

Figura 8. a) Fragmento de estela. València (MPDV N..$^{\circ}$ Inv. VE 1282); b) Restitución de una parte del epígrafe (Dibujo del autor).

Es un pequeño trozo de mármol del ángulo superior izquierdo de una estela rectangular. La superficie de campo epigráfico deja ver las marcas que dejó el artesano al trabajar el fondo de las letras con el puntero, un efecto que se contempla tantas veces en epígrafes andalusíes de todas las épocas, como vemos en los estudiados antes en los apartados 1 y 3 . Se aprecia un rebaje practicado por la parte externa de los dos costados conservados, tal vez hecho con la intención de encastrar alguna pieza en la estela, pero no se puede descartar que responda a una reutilización de la lápida en época posterior.

Además de ampliar el corpus de las inscripciones hasta ahora conocidas de la capital levantina, el fragmento presenta la novedad de sus características epigráficas, altamente interesantes. Puede calcularse por el texto restaurado que la lápida llegaría a medir unos 460-480 mm de anchura, una estimación que igualaría su tamaño con el calculado para el epitafio del príncipe de Alpuente antes mencionado.

\subsection{El epígrafe}

\section{Edición}

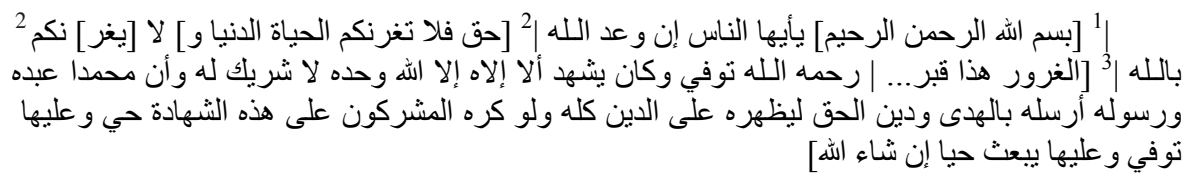

${ }^{2}$ Estos tres signos se grabaron sobre la línea y su trazo es de letra más pequeña. 


\section{Traducción}

[En el nombre de Dios, el Clemente, el Misericordioso “¡Hom]bres! La promesa de Dios [es verídica. iQue no os extravíe la vida mundanal] ni respecto de Dios os ex[travíe el seductor!" (Corán XXXV, 5). Ésta es la tumba de... ¡Tenga misericordia Dios de (él/ella)! Falleció... Daba testimonio que no hay más divinidad que Dios y que Mahoma es su siervo y su enviado. Él lo ha enviado "con la dirección y la religión verdadera para que prevalezca sobre todas las religiones aunque lo odien los asociadores" (Corán IX, 33). En esta creencia existió, en ella murió y en ella "será devuelto a la vida" (Corán XIX, 15), si Dios quiere].

\subsection{Comentario sobre el texto}

He restaurado las series de contenido religioso usadas en el período al que remite el estilo caligráfico, ya que en la segunda mitad del siglo XI el epitafio sigue la estructura: basmala, Corán XXXV, 5, nombre, fecha, šahāda, Corán IX, 33 y XIX, 15. La inclusión después de la basmala inicial de la aleya coránica XXXV, 5 es frecuente en epígrafes funerarios andalusíes de la segunda mitad del siglo XI, como ocurre en la mitad de los epitafios de Toledo fechados entre 451 y 468/1059 y 1075 (Barceló, 1990, 45). No es viable deducir si la estela se destinó a un hombre o a una mujer porque no conserva datos que podrían haber dado alguna pista al respecto, entre los que resultan fundamentales: nombre, verbo 'murió' o la jaculatoria que sigue al onomástico de la persona difunta (Fig. 8b).

El orden del formulario reconstruido se halla en València en estelas producidas después del ocaso de los herederos de 'Abd al-'Azīz Almanzor en el gobierno de la taifa (Barceló, 1998, 84), es decir tras la muerte de al-Ma'mūn de Toledo (467/1075), cuyo control sobre València había comenzado en 457/1065 y a quien sucedió brevemente su hijo al-Qādir (1075). Fue entonces cuando el poder regresó de nuevo a los amiríes en la persona de Abū Bakr Muhammad (1075-1085), nieto de 'Abd al-'Azīz (Huici, 1970, I, 188-197).

\subsection{Comentario epigráfico}

A primera vista, los caracteres epigráficos que se hallan en este fragmento se ven usados en algunos epígrafes de la época recogidos en la ciudad taifa de Toledo. De ellos, los fechados en el período 461-468/1072-1075 son los que tienen más elementos comunes con la inscripción que analizo. No sólo tienen 
unos rasgos cúficos muy similares, sino que se produce también la inclusión de caracteres olvidados de una palabra, entre líneas y con letra de menor tamaño (cf. Delgado, 1987, lám. XXXII, a y d). La semejanza entre el cúfico practicado esos años en Toledo y el que se documenta en València mueve a plantear que la presencia en ambas ciudades de al-Qādir fue la causa de que se impusiera cierta uniformidad en los alfabetos.

Puedo aducir que la altura media del diseño de alif es, en esta lápida, igual o muy similar a la registrada en los epígrafes toledanos de la etapa apuntada (4-4,5); también la valenciana y las toledanas de ese período comparten un cociente 6-8 en la proporción altura:anchura de alif, lo que significa una letra más esbelta; y en las inscripciones funerarias de ambas capitales el nexo Allāh presenta el segundo lām inclinado sobre $h \bar{a}$ ' final (Ocaña, 1983, fig. 12).

El diseño estilizado en los alifatos de ambas capitales explica la altura del remate final del signo 6a (grande, con apéndice recto), cuyo trazado es igual a 14a que ha perdido el ápice denominado "cuello de cisne". Sin embargo, mientras que el apéndice superior de la figura 11 en el fragmento de València es perpendicular a su cuerpo (Fig. 8a), dicho elemento se presenta en Toledo como una línea quebrada, aspecto que se repite en tantas otras muestras de escritura cúfica en esta centuria medieval. Esos rasgos se ven en estelas valencianas sin fecha de finales del siglo XI (Barceló, 1998, n. . 34, 35).

Con todo, la mayor semejanza con los caracteres de este fragmento se encuentra en una lauda -datada en 500-515/1106-1121- con la que comparte un alif de igual altura media $(40-45 \mathrm{~mm})$ e idéntico cociente de proporcionalidad (1:7). La única diferencia notable entre ambos es el uso de líneas o pautas grabadas en relieve en la lápida que sirve de comparación (Barceló, 1998, 182184, n. $\left.{ }^{\circ} 35\right)$. Los rasgos epigráficos de este trozo de estela guardan parecido con inscripciones de Almería de los años 488/1095 y 504/1112 (Ocaña, 1964, 19-23, n. ${ }^{\circ} 23-27$ ).

Puede ponerse en relación con el alifato de una placa datada en la década 485-495/1092-1102 (Barceló, 1998, n. ${ }^{\circ}$ A2) cuya relación con la taifa de Dénia he sugerido sin mucha convicción (Barceló, 2016a, 63, 3.4, fig. 9d). Pero he podido confirmar que esa lápida del Museo Arqueológico de Orihuela (N.$^{\circ}$ Inv. E-ISL 1 i 2) procede de la ciudad de Murcia. Refiere su hallazgo Rodrigo Amador de los Ríos en una nota publicada en 1902, que incluye medidas y lectura de la misma que despejan cualquier duda. En esa inscripción murciana (Barceló, 1998, fíg. LV) y en la valenciana ya citada (Barceló, 1998, fig. XXXV) apenas hay discrepancias notables en el trazado de sus letras.

Se trataría de la adopción de un nuevo modelo epigráfico traído a la taifa, tal vez, por el murciano Ibn Ṭāhir (455-471/1063-1071) visir del gobernante Yahyyà al-Qādir o del propio toledano; no en su primer y breve mandato (1075), sino 
tras la toma de Toledo por Alfonso VI en 478/1085. Esa segunda vez se instaló en el levante peninsular y dirigió su ya reducida taifa como mandatario impuesto. Por tanto, teniendo en cuenta las características del alfabeto árabe, se puede proponer para este fragmento una data en los años finales del siglo XI, coincidente con la presencia en València de al-Qādir (478-485/1086-1092), la posterior revuelta de Ibn Ŷaḥhāf (1092-1094) y el control de la ciudad por el Cid hasta su muerte y huida de las tropas castellanas tras el incendio de la capital (1094-1102).

\section{CONCLUSIONES}

Las estelas analizadas se grabaron sobre mármol, un material noble que desde la Antigüedad ha sido elegido para usos mortuorios. Como acontece en tantas etapas históricas, en época andalusí se recicla material antiguo, incluso conservando la inscripción que le grabaron en latín o los adornos que le hicieran los romanos. Aquí se ha podido comprobar esa reutilización en la inscripción de Xàtiva y podría ser el caso también del fragmento valenciano del portal de la Valldigna.

El ir y venir de piedras grabadas, si estas son de mármol, es otro comportamiento antiguo que, en el caso de las poblaciones costeras, puede ser susceptible de llegar a tierras lejanas por vía marítima, de cabotaje o larga travesía, como lastre estabilizador de una embarcación. O la lápida grabada con epígrafe pudo viajar acompañando el botín de guerra de algún soldado y la piedra puede acabar expuesta en alguna iglesia o edificio señorial como si fuera un trofeo. Es lo que posiblemente ocurrió con las dos porciones de inscripción árabe que guarda hoy el Museo de León, que pudieron llegar desde la taifa toledana a la Montaña a fines del siglo XI.

Un repaso rápido por las medidas que en las estelas valencianas proporciona el formato de la letra alif da un tamaño que oscila levemente entre 35 mm y $45 \mathrm{~mm}$, con escasa variación en las inscripciones del siglo XI. Así se aprecia también en los alfabetos datados que aquí se publican, procedentes de Xàtiva (429/1038) y de Alpuente (447/1055). Si en principio esa fue también la tónica de la taifa de Valencia, cuyo alifato mantiene un módulo parecido, su coeficiente sólo será alterado al final de la centuria cuando, siguiendo el modelo toledano, las letras se estilizan, sus siluetas se adelgazan, la base se amplía y el alif adquiere la proporción 1:7, pero levemente alejado del módulo 1:6 introducido por la dinastía almorávide que lo mantendrá inalterado durante el tiempo de su dominio sobre la provincia de al-Andalus.

El tercer aspecto de estos epígrafes analizados de las taifas es que prueban la rapidez con que se introducen en los modelos de escritura pública los cam- 
bios impuestos por las élites que controlan el territorio. Sorprende la rápida influencia del tipo cúfico toledano en los últimos años del dominio taifa valenciano, aspecto que merece por sí solo un estudio de mayor profundidad de la aquí expuesta.

\section{APÉNDICE}

\section{Datos de las características de las lápidas estudiadas}

En las descripciones uso la ficha de Barceló (1998; fecha, definición, lugar de hallazgo, procedencia, depósito, materia, forma, medidas, faja de enmarque, $n .{ }^{\circ}$ líneas, caja de escritura, altura media de alif, conservación). Las abreviaturas: A, altura; G, grosor; L, latitud; N. ${ }^{\circ}$ Inv. número de inventario. Las siglas de los museos: Bellas Artes San Pío V, Valencia MBA; Prehistoria, Diputación de Valencia MPDV; SIAM Servicio de Investigación Arqueológica Municipal, Ajuntament de València.

1. 10 ŷumādà I [4]29 = 18 febrero 1038. Estela funeraria. Excavaciones. Xàtiva. Museu de l'Almodí (Xàtiva). Mármol de Buixcarró rectangular con enmarque. A 400 x L 700 x G 105 mm. 25 mm. 8 horizontales. A 350 x L 650 mm. alif: 40 mm. La pieza se rescató completa, está en excelente estado, pero ha perdido casi todo el listel del lado superior y un golpe ha afectado a la última palabra de la primera línea. En el envés conserva varias acanaladuras en el canto superior. Bibliografía. Edición: inédita. Hay traducción, estudio y reproducción (Barceló, 2007, 46-47).

2. [420-440 = 1029-1049]. Estela funeraria. Montaña leonesa (?). Toledo (?). Museo de León. N. ${ }^{\circ}$ Inv. 2006/35. Mármol blanco rectangular. A 246 x L 162 x G 45 mm. Si tuvo faja no se conserva. 5, incompletas. A 246 x L $162 \mathrm{~mm}$. alif: $30 \mathrm{~mm}$. Su estado es bueno, aunque no afecta el epígrafe el resto de una pequeña perforación circular en la derecha. La pieza tiene forma ligeramente trapezoidal a consecuencia de la rotura de la lápida. Bibliografía. Inédita.

3. [440-460 = 1048-1068]. Estela funeraria. Vega de Boñar (León). Toledo (?). Museo de León. N. ${ }^{\circ}$ Inv. 508/2824. Mármol blanco rectangular con enmarque. A 260 x L 410 x G $45 \mathrm{~mm} .20 \mathrm{~mm}$, superior $27 \mathrm{~mm}$. 5, casi completas. A 233 x L $390 \mathrm{~mm}$. alif: $45 \mathrm{~mm}$. La estela está en excelente estado. Para acomodar la pieza a su nuevo destino y pudiera servir de losa por el revés se le recortaron los lados izquierdo e inferior; en el lateral derecho se le practicó un orificio, que apenas afecta al texto, tal vez para la mejor sujeción a un punto desconocido. Bibliografía. Edición inédita. Traducción: Ríos (1883, 238-240), de quien la toman Gómez Moreno (1925, I, 171-172 y II, lám. 159) y Grau Lobo (1993, 102-103, lám. 53b), que dan reproducción.

4. Domingo 13 raŷab $447=8$ octubre 1055. Estela funeraria. Hallazgo fortuito. Alpuente (València). Colección particular. Mármol gris de grano fino rectangular con enmarque. A 250-110 x L 240-180 x G 70-50 mm. $50 \mathrm{~mm}$. 4, parciales. A 200-110 x L 180-130 mm. alif: $35 \mathrm{~mm}$. Algo maltrecha, aunque la rotura no impide interpretar 
un texto cuya lectura coincide con el suplido en las líneas 7 y 8 del epitafio de ' $I z z$ aldawla de Alpuente conservado en MBA. N. ${ }^{\circ}$ Inv. 1482 (Barceló, 1998, 153-154 n. ${ }^{\circ}$ 17). Bibliografía. Edición y traducción inéditas. Reproduce: DIVAL. Revista de la Diputación, 5 (mayo 2001), 24.

5. [450-499 = 1058-1106]. Zócalo funerario. Excavación. València. SIAM. N. ${ }^{\circ}$ Inv. 1/803. Mármol blanco rectangular con enmarque. A 110 x L 68-111 x G 42-48 mm. 23 mm. 1, incompleta. A 40 x L 80 mm. alif: 40 mm. Los signos están en buen estado. La cara anterior fue pulida y los lados desbastados, mientras que la posterior presenta una marca circular que evidencia la reutilización de la pieza como quicio de puerta o ventana. Sobre la banda externa superior se aprecia un pequeño rebaje que sugiere que en algún momento estuvo embutida en otro objeto. Conserva resto de la faja de enmarque en el lado derecho y es fácil deducir, a pesar de la rotura de la pieza, que formaba ángulo con otra similar. Bibliografía. Inédita.

6. [485-515 = 1092-1122]. Estela funeraria. Excavación. València. MPDV N. ${ }^{\circ}$ Inv. VE 1282. Mármol blanco rectangular con enmarque. A 142-43 x L 241 x G 48-42 mm. 16 mm. 2, una casi perdida. A 102-28 x L 215 mm. alif: 43 mm. Los signos están en buen estado. La cara posterior fue pulida y los lados desbastados. Ofrece un rebaje de sus bandas externas, lo que sugiere que en algún momento estuvo encastrada en algún marco. Como consecuencia de la rotura de la pieza, el fragmento tiene forma trapezoidal pero aún mantiene parte de la primera línea y restos del final de la siguiente. Bibliografía. Inédita (Armengol, 2014).

\section{BIBLIOGRAFÍA}

ARMENGOL, Pau (2014): Inscripció aràbiga apareguda a 1PDVALL, informe inédito sin paginar depositado en el MPDV.

ÁVILA, Mª L. (1990): “Andalusíes en el Wāfī bi-l-wafayāt”, en L. Molina (ed.), Estudios onomástico-biográficos de al-Andalus. IV, Granada, CSIC, 159-214.

ÁVILA, Ma L. y MARÍN, M. (1995): "Nómina de sabios de al-Andalus (430520/1038-1126)", en M. Marín y H. de Felipe (eds.), Estudios onomástico-biográficos de al-Andalus. VII, Madrid, CSIC, 55-190.

BARCELÓ, C. (1990): "Estructura textual de los epitafios andalusíes (siglos IX-XIII)", en Homenaje a Manuel Ocaña Jiménez, Córdoba, Diputación Provincial, 41-54.

BARCELÓ, C. (1998): La escritura árabe en el país valenciano, Valencia.

BARCELÓ, C. (2001): "Làpida funerària de Murbātitir (Sagunt, segle X)", Stvdia Philologica Valentina, 5.2, 169-177.

BARCELÓ, C. (2006): “Un epitaffio islamico proveniente da Maiorca portato a Pisa come trofeo di guerra?", Quaderni di Studi Arabi. Nuova Serie, I, 55-68.

BARCELÓ, C. (2007): "Epitafio islámico", en X. Company, V. Pons y J. Aliaga (com.), La Llum de les Imatges. Lux Mundi. Xàtiva, Valencia, Generalitat Valenciana, 46-47.

BARCELÓ, C. (2013): "Lisboa y Almanzor (374 H. / 985 d.C.)”, Conimbriga, 52, 165-194. 
BARCELÓ, C. (2015): “Corpus epigráfico andalusí andalusí ¿un proyecto posible?”, en A. Malpica y B. Sarr (eds.) Epigrafía Árabe y Arqueología Medieval, Granada, Alhulia, 173-204.

BARCELÓ, C. (2016a): "Epitafis de la taifa de Dénia (1012-1092)”, Aguaits. Revista d'investigació i assaig, 36, 35-69.

BARCELÓ, C. (2016b): “Epigrafía funeraria nazarí: epitafio de al-Yanaštī (835/1435), Arqueología y Territorio Medieval, 23, 41-55.

BARCELÓ, C. (2016c): "Epigrafía árabe en la colección Monsalud”, Boletín del Museo Arqueológico Nacional, 34, 269-286.

BARCELÓ, C. (2016d): "Epígrafe fundacional hudí de la azuda de Tarazona", Mainake, 36, 99-110.

BARCELÓ, C. y LABARTA, A. (2019): “Lápida árabe en la ermita de Nuestra Señora de la Vega (Torre de Juan Abad, Ciudad Real)", Vínculos de Historia, 8, 216-231.

BASSET, H. y LEVI-PROVENÇAL, E. (1922): "Chella. Une nécropole mérinide", Hésperis, 2, 1-92, 255-316, 385-422.

CORTÉS, J. (1980), El Corán. Edición, traducción y notas, Madrid, Editora Nacional.

DELGADO VALERO, C. (1987): Materiales para el estudio morfológico y ornamental del arte islámico en Toledo, Toledo, Museo de Santa Cruz.

DÍAZ ESTEBAN, F. (1987): "Dos nuevas inscripciones árabes de Trujillo y relectura de una tercera", en Homenaje al Prof. Darío Cabanelas, Granada, Universidad de Granada, vol. II, 171-181.

GARCÍA GÓMEZ, E. (1947): "La inscripción de la pila árabe de Santander”, Al-Andalus, 12.1, 155-161.

GÓMEZ AYLLÓN, E. E. (2006): Inscripciones árabes de Toledo: época islámica, Madrid (tesis doctoral. Universidad Complutense de Madrid). Consultada en: http:// eprints.ucm.es/tesis/fll/ucm-t29552.pdf

GÓMEZ MORENO, M. (1925): Catálogo monumental de la provincia de León (19061908), Madrid, Ministerio de Instrucción Pública y Bellas Artes, 2 vols. [ed. facsímil, León, 1979].

GRAU LOBO, L. A. (1993): “Ficha 53”, en Guía-Catálogo de 100 piezas. Objetos de Historia. Museo de León, Junta de Castilla y León, 102-103.

GUARDIOLA, Ma . D. (1990): “Andalusíes en dos obras de al-Suyūṭ̂̄”, en L. Molina (ed.) Estudios onomástico-biográficos de al-Andalus IV, Granada, CSIC, 215-324.

HUICI MIRANDA, A. (1970): Historia musulmana de Valencia y su región. Novedades y rectificaciones, 3 vol., Valencia, Ayuntamiento de Valencia.

LABARTA, A. (1992): "Tres nuevos fragmentos de la lápida de un Abencerraje”, AlQanțara, 13.2, 537-539.

LABARTA, A. (2015): "Epigrafía árabe sobre piedra en el Garb al-Andalus", en A. Malpica, y B. Sarr (eds.) Epigrafía Árabe y Arqueología Medieval, Granada, Alhulia, 205-238.

LEVI-PROVENÇAL, E. (1931): Inscriptions arabes d'Espagne, París, Maissonneuve - Leiden, Brill.

LEVI-PROVENÇAL, E. (1934): "Deux nouvelles inscriptions arabes de Tolède", Anuario del cuerpo facultativo de archiveros, bibliotecarios y arqueólogos, 1.2, 147-149. 
MANZANO, A. (2005): “¿Un contemporáneo del Profeta en la Península Ibérica? Acontecimiento arqueológico de primera magnitud", Islam y al-Andalus. Boletín Informativo de la Yama'a islámica de al-Andalus, n. 39 (junio 2005), 1-10. Consultado (12-12-2005) en: http://www.islamyal-andalus.org/

MARÇAIS, W. (1900): "Note sur trois inscriptions arabes du Musée de Tlemcen”, Bulletin archéologique du Comité des travaux historiques et scientifiques, 163-165.

MARTÍNEZ NÚÑ̃Z, M. ${ }^{a}$ A. (2013): Epigrafía árabe del Museo Arqueológico Provincial de Badajoz, Badajoz, Museo Arqueológico Provincial de Badajoz.

MEMORIA de los trabajos llevados a cabo por la Sociedad Arqueológica Valenciana durante el año 1872, Valencia, 1873.

OCAÑA, M. (1945): “Zócalos hispanomusulmanes del siglo XII”, Al-Andalus, 10.1, 164-169.

OCAÑA, M. (1954): “Tres epitafios musulmanes toledanos del siglo XI”, Al-Andalus, 19.2, 407-410.

OCAÑA, M. (1964): Repertorio de las inscripciones árabes de Almería, Madrid - Granada, CSIC.

OCAÑA, M. (1970): El cúfico hispano y su evolución, Madrid, IHAC.

OCAÑA, M. (1983): "La epigrafía hispano-musulmana durante le periodo de Taifas y Almorávides", en Actas del IV Coloquio hispano-tunecino (Palma de Mallorca, 1979), Madrid, IHAC, 197-204.

OCAÑA, M. (1988): "Historia y epigrafía en la Almería islámica", en Almería en la Historia. Homenaje al Padre Tapia, Almería, Monte de Piedad y Caja de Ahorros, 173-188.

PASCUAL, J. y MARTÍ, J. (2002): "El recinto fortificado de la Valencia musulmana", en I. C. F. Fernandes (coord.) Mil anos de fortificações na Península Ibérica e no Magreb (500-1500), Lisboa, Câmara Municipal de Palmela, 291-309.

PRIETO VIVES, A. (1926): Los Reyes de Taifas. Estudio histórico-numismático de los musulmanes españoles en el siglo V de la Hégira (XI de J.C.), Madrid, Mestre.

PUJANTE MARTÍNEZ, A. (2008): "El cementerio del solar de calle Poeta Jara Carrillo, número 6 con calle Conde Valle de San Juan, número 5, Murcia”, en M. Le-

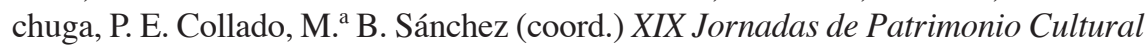
de la Región de Murcia, Murcia, Tres Fronteras, vol. I, 319-322.

RÍOS, R. A. de los (1883): Museo Arqueológico Nacional. Memoria acerca de algunas inscripciones arábigas de España y Portugal, Madrid, Fortanet.

RÍOS, R. A. de los (1902): "Monumentos funerarios de los musulmanes, hallados recientemente en Murcia y en Jaén”, La Ilustración Española y Americana, 41 (8 de noviembre), 271-272.

ROSSELLÓ-BORDOY, G. (1998): “Algunas reflexiones sobre el cúfico toledano en base a un nuevo texto de fundación”, Revista del Instituto Egipcio de Estudios Islámicos en Madrid, 30, 155-180.

VERNET, J. (1963): El Corán. Nueva traducción, introducción y notas, Barcelona, Planeta.

ZOZAYA, J. (1990): "Un cipo funerario procedente de Calatrava la Vieja", Boletín de Arqueología Medieval, 4, 311-320. 
